\title{
LA FUNCIÓN DE LAS MAQUILADORAS COMO ESLABÓN DE CRECIMIENTO INDUSTRIAL PARA MÉXICO. EL CASO DE YUCATÁN
}

\author{
Alba Rosa Rivera de la Rosa \\ Maestra en Economía por la Universidad Nacional Autónoma de México. \\ Realiza sus estudios de Doctorado con la Universidad de Sevilla, España. \\ Funcionaria hace algunos años en Nacional Financiera S.N.C. en el área \\ de Organismos Multilaterales. Docente en diferentes Universidades del estado \\ de Yucatán. Actualmente es responsable de la Coordinación de Posgrado \\ e Investigación de la Facultad de Economía de la Universidad Autónoma \\ de Yucatán.
}


La existencia de las maquiladoras en países como México obedece a un orden mundial en que las empresas multinacionales ya sean norteamericanas, japonesas, coreanas, etc., desean incrementar sus márgenes de ganancia a través de la contratación de mano de obra barata. En sus países de origen estas empresas contratan normalmente trabajadores con salarios que afectan sus costos y por lo tanto sus niveles de rentabilidad.

México y específicamente Yucatán mantiene una ventaja comparativa en abundancia de mano de obra, además de otros factores como: cierta tranquilidad política, confianza en la cooperación estatal o federal para la instalación de la infraestructura necesaria, personal joven, dócil y trabajador, bajos salarios, un mínimo de desarrollo industrial, etc. elementos que han sido determinantes para que las maquiladoras sigan llegando al estado.

Al definir a una maquiladora como una empresa que ensambla, manufactura, procesa o repara materiales temporalmente importados por el país receptor (en este caso México) para su eventual reexportación (Álvarez, 1993), nos damos cuenta que en realidad, "los procesos de integración productiva mundial que utilizan el sistema de contratación y maquila que han incorporado a países centroamericanos y México no generan nuevas capacidades tecnológicas, aún cuando algunas de ellas forman parte de las ramas más dinámicas a nivel mundial - por ejemplo la electrónica- de tal forma que rompen la capacidad de escalar tecnológicamente". (Sánchez, 2004)

La maquiladora entonces, no tiene un papel fundamental para posicionar al país receptor en cuanto a desarrollo tecnológico se trata, pero genera empleo, salarios y por supuesto un cierto excedente o ganancia. El empleo y salarios tendrán impacto en el mercado interno del país maquilador o receptor, no obstante, el excedente o ganancia fluirá a su país de origen o a otro destino. El proceso de acumulación y ahorro así como los factores de desarrollo e innovación tecnológica no estarán presentes en el país receptor o maquilador.

Por lo tanto, ya que el excedente o ganancia no es acumulado en el país maquilador que generarían condiciones de expansión productiva, desarrollo tecnológico y acumulación de capital, entonces, deben instrumentarse mecanismos a través de los cuales se pueda aprovechar la presencia de la 
maquiladoras para aprender, innovar y conectar empresas nacionales a la producción de las maquiladoras a través de encadenamientos productivos. De esta manera se crean las condiciones internas para tener avance en el desarrollo industrial del país receptor.

En Yucatán las maquiladoras han cumplido su papel de dar empleo y salarios que aunque bajos, han estimulado los mercados internos, sin embargo el proceso de encadenamientos productivos parece no haber jugado todavía un papel central.

¿Es posible desencadenar o acelerar este proceso en los países que albergan temporalmente a las maquiladoras? ¿Cómo puede aprovechar México y específicamente Yucatán la presencia de estas empresas?

Me parece que la respuesta ya la han dado otras experiencias en el mundo, como es el caso de Corea y Taiwán.

El continente asiático ha jugado el papel de ganador en el proceso de globalización. Este proceso, es decir, la globalización podemos definirla como lo hace Manuel Delgado, (Delgado, 1998) "...es la internacionalización de la producción, la comercialización y los financiamientos; conjugando innovación en todos los aspectos productivos incluyendo la información y la conexión de redes y canales ligados a la producción y comercialización, se rompen fronteras y se aceleran los flujos productivos. A través de diferentes medios que pueden ser desde maquilar en los países más remotos hasta generar proyectos de inversión en países nuevos o emergentes, las multinacionales ahora tienen ganancias inimaginables maximizando su rentabilidad."

Los países asiáticos pudieron integrarse a este proceso de globalización de una manera exitosa gracias a determinadas políticas públicas que incluyeron desde el dinamismo de su sector agrícola hasta utilizar los préstamos provenientes de organismos multilaterales exclusivamente para inversiones productivas.

Corea ha mantenido políticas económicas en donde las pequeñas y medianas empresas se han articulado de una manera exitosa a los grandes conglomerados industriales. 
Las políticas gubernamentales han estado encaminadas a apoyar técnica y financieramente a estas empresas con el fin de que abastezcan con altos niveles de calidad, piezas y componentes estratégicos que no son fabricados por las grandes empresas. Esta articulación ha sido fundamental para generar altos niveles de empleos y sobre todo el capital coreano invertido en su propio país aseguró la generación de un proceso de acumulación.

Actualmente Corea produce exitosamente electrodomésticos y computadoras entre otros bienes manufacturados.

El caso de Taiwán es muy similar, en 1980 este país ya contaba con 700,000 medianas y pequeñas empresas, que representaban el 70\% del empleo, el 55\% del producto nacional bruto y el $62 \%$ de las exportaciones manufactureras. (ONUDI, 1996)

Estas empresas medianas y pequeñas son de capital taiwanes y al igual que Corea están totalmente articuladas a las grandes empresas de capital extranjero fundamentalmente chino y japonés.

Otro rasgo importante es que los gobiernos de estas naciones han dado incentivos impositivos para que se aumenten los niveles de exportación y se lleven a cabo esfuerzos en investigación y desarrollo tecnológico.

Para 1994 los niveles de ingreso per-cápita de Corea y Taiwán ascendían a 7,417 y 9,654 dólares de 1990 respectivamente. Para ese mismo año México y Brasil mantenían niveles de 2,124 y 2,268 dólares de 1990.

Para el año del 2007 según cifras del Fondo Monetario Internacional Corea del Sur mantiene un per-cápita de 25,403 dólares anuales, Taiwán 31,692, mientras que en México y Brasil fueron de 11,761 y 9,531 respectivamente.

Como podemos observar el desarrollo tecnológico genera un círculo virtuoso entre acumulación, financiamientos, empleo y salarios que impactan favorablemente los mercados internos y los externos. Se elevan los niveles de vida y se crean las condiciones de la expansión económica. 
La política industrial en México no ha generado hasta el momento las posibilidades de una producción competitiva que abastezca los mercados. En muchos casos resulta más redituable importar productos del exterior con precios bajos, que producirlos internamente. Las consecuencias de este proceso es un bajo crecimiento económico.

La experiencia asiática demostró al mundo la posibilidad de un crecimiento vertiginosamente rápido de desarrollo industrial, sus empresas grandes y pequeñas pudieron coordinarse para llevar a cabo esta tarea. Normalmente no es recomendable para ningún país tomar modelos de desarrollo de otras naciones y adoptarlos tal cual. Las raíces históricas específicas de cada realidad marcan necesidades, usos y costumbres que llevan a diferencias culturales, políticas, sociales, etc. que impiden que esos procesos de adaptación tengan los mismos resultados no obstante, la experiencia de los países asiáticos bien valdría la pena tomarla en cuenta. Las razones están en el hecho de que México es un país predominantemente maquilador. Los retos que México y Yucatán en específico deben enfrentar están en relación a la articulación de pequeñas y medianas firmas con las maquiladoras, surtiendo o abasteciendo paulatinamente partes de la producción o insumos.

Actualmente, dentro de los planteamientos de la política de financiamientos está la propuesta de créditos a microempresarios y a medianas y pequeñas empresas, pero no se ha incluido una política de créditos preferenciales a pequeños y medianos empresarios que ligados específicamente a la producción textil, de acero, del vidrio, etc. proporcionen piezas o componentes a grandes consorcios nacionales o extranjeros como las maquiladoras.

Por otra parte, el caso del campo mexicano es crucial y hacia allá debería de estar concentrada también la política crediticia y sobre todo la asistencia técnica. Gran parte de las materias primas y de los insumos para la industria provienen de este sector. Mientras parte de las importaciones del país se destinen para consumo e insumos primarios y no existan incentivos hacia la producción interna del sector primario va a ser difícil que se pueda pensar en destinar recursos de importancia hacia la inversión productiva industrial.

Las metas de todo desarrollo económico está ligado con una estructura industrial y agrícola bien cohesionadas. Los países que mantengan estas 
estructuras al margen del desarrollo se quedan fuera de las posibilidades de integrarse exitosamente en el mundo globalizado.

Las maquilas tienen una función estratégica en el desarrollo industrial nacional. Si bien las primeras maquiladoras que llegaron a México en la década de los 6os. estuvieron destinadas únicamente a cumplir el papel de absorber el desempleo de la frontera norte para solucionar en parte la migración de braceros a Estados Unidos. Ahora los retos de la política industrial están al interior del país, con la articulación industrial de grandes empresas con las pequeñas y elevar con ello las posibilidades de mayor competitividad internacional.

BaLANZA COMERCIAL dE MÉXICO A DICIEMBRE DE 2008

\begin{tabular}{|c|c|c|c|c|}
\hline \multirow[b]{2}{*}{ Concepto } & \multicolumn{2}{|c|}{ Diciembre } & \multicolumn{2}{|c|}{ Enero-Diciembre } \\
\hline & $\begin{array}{l}\text { Millones de } \\
\text { Dólares }\end{array}$ & $\begin{array}{c}\text { Variación } \% \\
\text { anual }\end{array}$ & $\begin{array}{c}\text { Millones de } \\
\text { Dólares }\end{array}$ & $\begin{array}{c}\text { Variación \% } \\
\text { anual }\end{array}$ \\
\hline Exportaciones Totales & $\underline{18,686.1}$ & (-) 19.7 & $\underline{291,806.6}$ & $\underline{7.3}$ \\
\hline Petroleras & $1,739.3$ & $(-) \overline{58.2}$ & $50,638.6$ & $\overline{17.7}$ \\
\hline No petroleras & $16,946.8$ & $(-) 11.3$ & $241,168.0$ & 5.4 \\
\hline Agropecuarias & 713.7 & $(-) \quad 2.8$ & $8,389.2$ & 12.8 \\
\hline Extractivas & 134.2 & $(-) 23.7$ & $1,931.0$ & 11.2 \\
\hline Manufactureras & $16,098.9$ & $(-) 11.5$ & $230,847.8$ & 5.1 \\
\hline Importaciones Totales & $\underline{20,752.6}$ & (-) 12.8 & $\underline{308.644 .7}$ & $\underline{9.5}$ \\
\hline Bienes de consumo & $3,424.1$ & (-) 17.2 & $47,941.7$ & 11.4 \\
\hline Bienes intermedios & $13,916.1$ & (-) 16.5 & $221,599.1$ & 7.9 \\
\hline Bienes de capital & $3,412.4$ & 13.8 & $39,103.8$ & 16.4 \\
\hline Saldo de la Balanza Comercial & (-) $\underline{2.066 .5}$ & $\underline{285.7}$ & (-) 16.838 .1 & $\underline{67.1}$ \\
\hline
\end{tabular}

Nota: Debido al redondeo la suma de los parciales puede no coincidir con el total.

Fuente: Página del INEGI (www.inegi.gob.mx), Comunicados de prensa. Información oportuna sobre la Balanza Comercial de México durante diciembre de 2008. Comunicado No. 012/09. Enero 2009 Aguascalientes, Ags.

Si revisamos las cifras del Comercio Exterior en México y analizamos el cuadro arriba mencionado se desprenden varias conclusiones; primero, para el año de 2008 el déficit de la Balanza Comercial ascendió a (-) 16,838.1 millones de dólares, este déficit representa una posición de gran vulnerabilidad de México con respecto a los mercados externos, son necesarias cada vez más importaciones para abastecer los mercados internos. Segundo, del total de 
nuestras importaciones para el año 2008 el 72\% corresponden a Bienes intermedios, estos bienes representan insumos indispensables para la producción. Si tomamos en cuenta que mucha de esa producción se exporta, entonces México depende en un 70\% de sus importaciones para poder exportar, de tal suerte que cualquier inestabilidad de nuestra moneda que tienda hacia una devaluación terminará por afectar la competitividad de nuestros productos al hacer más caras las importaciones de los insumos. Tercero, México es predominantemente un país manufacturero del total de la exportaciones para este año el $80 \%$ corresponden a manufacturas.

No obstante, aunque no podemos saber el dato exacto de la producción manufacturera que proviene de las maquilas y cual de empresas que no maquilan, sabemos que la producción de maquilas es fundamental para México por los datos de Inversión Extranjera Directa que se registra año con año en nuestra Balanza de Pagos, este fenómeno nos hace dependientes de las condiciones de los mercados extranjeros y de la capacidad de captar Inversión Extranjera Directa. (1)

En Yucatán y para el año de 1999 la Inversión Extranjera Directa ascendió a 25.7 millones de dólares para el año del 2006 esta cifra desciende a 15.5 millones de dólares, es decir que muchas maquiladoras han emigrado a otros puntos del planeta. (2)

En el 2009 se prevé que las maquilas sigan abandonando al Estado de Yucatán, ya sea por la crisis norteamericana que afectará a gran parte del mundo o por la propia inercia de la recesión en México.

El desempleo podría también agudizarse con el retorno de trabajadores migratorios y algunos indicadores económicos como el tipo de cambio tenderán a presentar inestabilidad ya que la estabilidad de este indicador ha dependido en gran medida de las remesas que los trabajadores migratorios envían a

(1)Para el año 2007 se abrió la página del INEGI con la siguiente observación para las exportaciones manufactureras, "...en las estadísticas de comercio exterior ya no se distinguirá a las empresas maquiladoras del resto de las firmas exportadoras de productos manufacturados. Por lo tanto, la exportación manufacturera se difundirá en un solo rubro.

(2)Para el INEGI este rubro pertenece básicamente a los movimientos financieros y de insumos de las maquiladoras. 
México, es decir, mientras existan reservas de divisas suficientes en el Banco de México el peso puede mantenerse sin devaluarse. (3)

Debido a lo anterior y por razones estratégicas del comercio mundial, servicios, desarrollo industrial, etc., o por la existencia de otras regiones que ofrecen mejores condiciones en cuanto a los encadenamientos productivos. China, la India, Brasil, etc. son países que presentan cifras altas de Inversión Extranjera Directa.

Estos países ofrecen no sólo mano de obra barata, sino condiciones competitivas en cuanto a servicios y encadenamientos productivos.

Si el país no se prepara para enfrentar una sustitución de importaciones que permita la disminución de la importación de insumos a través de la incorporación de pequeñas firmas al proceso productivo y que son necesarias para la producción de los bienes exportables, entonces cualquier movimiento del tipo de cambio hacia su devaluación mantendrá a las exportaciones sin posibilidad de competir en los mercados.

Debido a las condiciones mundiales en las que se inserta nuestro país la devaluación será una posibilidad constante y se pondrá en grave riesgo no sólo la estabilidad monetaria sino la capacidad de México para mantener una competitividad externa.

La política económica industrial parece no tomar en cuenta estos focos rojos que tendrán un alto costo social y económico para el país.

Los encadenamientos productivos están en nuestras manos. Yucatán tiene la oportunidad de visualizar estas alternativas, lo haremos?

(3) Otras fuentes de entrada de divisas además de las remesas son; nuestras exportaciones, ventas de petróleo, turismo, etc. 


\section{REFERENCIAS}

Álvarez Icaza Longoria "Marco Teórico de la industria maquiladora de exportación" en Comercio Exterior. Mayo 1993.

Sánchez Daza, Germán.- "Integración: Los retos productivos de América Latina" en Integración en América Latina y Perspectivas del ALCA. El Economista Mexicano. Nueva época No. 8 Oct-Dic 2004.

Delgado Cabeza Manuel.- Globalización ¿nuevo orden o crisis del viejo? Desde el Sur. Cuadernos de Economía y Sociedad, Mayo 1998. Universidad de Sevilla, España.

Organización de las Naciones Unidas para el Desarrollo Industrial (ONUDI) Desarrollo Industrial. Informe Mundial 1996. FCE 1996. 